\title{
Why is There a Spike in the Job Finding Rate at Benefit Exhaustion?
}

\author{
Jan Boone · Jan C. van Ours
}

Published online: 10 April 2012

(C) The Author(s) 2012. This article is published with open access at Springerlink.com

\begin{abstract}
Putting a limit on the duration of unemployment benefits tends to introduce a "spike" in the job finding rate shortly before benefits are exhausted. Current theories explain this spike from workers' behavior. We present a theoretical model in which also the nature of the job matters. End-of-benefit spikes in job finding rates are related to optimizing behavior of unemployed workers who rationally assume that employers will accept delays in the starting date of a new job, especially if these jobs are permanent. This gives some workers an incentive to not immediately start
\end{abstract}

This paper has benefited from comments of participants in workshops and seminars at Bocconi University (Milano), Melbourne University (Department of Economics), QUT (Brisbane), Australian National University (RSSS) and Tilburg University (Department of Economics), Universität Zürich (IEW), Munich (CES), Linz.

Jan Boone gratefully acknowledges financial support from NWO (grant number 453.07.003).

J. Boone

Department of Economics, Tilec, CentER, Tilburg University, Tilburg, The Netherlands

e-mail: j.boone@uvt.nl

J. C. van Ours $(\varangle)$

Department of Economics, CentER, Tilburg University, Tilburg, The Netherlands

e-mail: vanours@uvt.nl

J. Boone · J. C. van Ours

CEPR, London, UK

J. C. van Ours

Department of Economics, University of Melbourne, Melbourne, Australia

J. C. van Ours

CESifo, Munich, Germany

J. Boone $\cdot$ J. C. van Ours

IZA, Bonn, Germany 
working after they have found a job. Instead they wait until their benefits expire. We use a dataset on Slovenian unemployment spells to test this prediction and find supporting evidence. We conclude that the spike in the job finding rate suggests that workers exploit unemployment insurance benefits for subsidized leisure.

Keywords Unemployment benefits · Spikes

JEL Classification $\mathrm{J} 22 \cdot \mathrm{I} 31 \cdot \mathrm{J} 16$

\section{Introduction}

In theory, unemployment benefits provide a disincentive to benefit recipients. The greater the level of benefits relative to the expected wage, the less costly the period of the job search, so workers tend to search for jobs less intensely and tend to remain unemployed longer. Putting a limit on the duration of benefits tends to speed up the job search. As the date approaches when benefits will expire, unemployed workers may increase the intensity of their job search and thereby the rate of job-finding. Moreover, many empirical studies find that the exhaustion of benefits creates a "spike" in the exit rate from unemployment. Usually, these spikes are found as a "by-product" of an analysis focusing on the relationship between potential benefit duration (PBD) and exit rates from unemployment.

Moffitt (1985) is an example of an early US study finding benefit exhaustion spikes. He analyzes administrative unemployment insurance records from the Continuous Wage and Benefit History $(\mathrm{CWBH})$ database. As Moffitt indicates the main advantage of administrative data is the high accuracy, while the main disadvantage is that the variable of interest, the duration of UI benefits is truncated at the point of maximum benefits. Most individuals in his data have a maximum benefit duration of 26 weeks but some individuals are entitled to extended benefits up to 13 weeks. Moffitt finds that the unemployment exit rate at 26 weeks is 3 times the exit rate one month before benefit expiration. At 39 weeks there is a spike in the exit rate which is about 2 times the regular exit rate. Meyer (1990) analyzes the same CWBH data as Moffitt using a more extensive statistical model finding similar results: the exit rate in the week before benefit exhaustion is about twice the size of the usual exit rate. Katz and Meyer (1990a) use two datasets, the CWBH dataset and data from the Panel Study of Income Dynamics. The results concerning the spike at benefit exhaustion using the CWBH data are similar to previous studies: in the week of benefit expiration the exit rate is about $80 \%$ higher. The survey data allow for a distinction between transitions to jobs at the previous employer (recalls) and transitions to new jobs. In both cases there is a substantial increase in the job finding rate close to benefit exhaustion. ${ }^{1}$ Katz and Meyer (1990b) use CWBH data supplemented with telephone interviews to provide additional information. They find spikes in the job finding rates in the exhaustion week which are 2.2-2.3 times the usual job finding rate, both for recalls and new jobs. Card

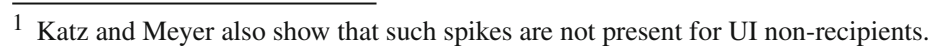


and Levine (2000) analyze administrative data from the New Jersey Extended Benefit Program. They find that the exit rate in the week of benefit exhaustion is about twice as large as the regular exit rate.

There are also quite a few European studies that find spikes near benefit exhaustion. Carling et al. (1996) analyze Swedish data and find a big increase in the outflow from unemployment to labor market programs whereas the increase in the exit rate to employment is substantially smaller. Roed and Zhang (2003) find for Norwegian unemployed that the exit rate out of unemployment increases sharply in the months just prior to benefit exhaustion with the effect being larger for females than for males. Adamchik (1999) finds a strong increase in re-employment probabilities around benefit expiration in Poland. Lalive et al. (2006) analyze Austrian social security data finding large spikes in the exit rate out of unemployment at benefit exhaustion. Van Ours and Vodopivec (2006) studying PBD reductions in Slovenia find both strong effects on the exit rate out of unemployment and substantial spikes around benefit exhaustion; the spikes in the job finding rate in the month prior to benefit exhaustion are 2.2-2.5 times as high as the usual job finding rate. In a recent study that focuses exclusively on the end-of-benefit spike phenomenon Card et al. (2007) find that the unemployment exit rate increases much more than the re-employment hazard rate does. Their main conclusion is that the spike in unemployment-exit rates is to a large extent due to measurement error. Researchers mistake leaving the unemployment register for job finding.

Part of the criticism by Card et al. (2007) on previous studies may be valid as some studies are based on unemployment exits up to point of benefit exhaustion only. But, there are also studies focusing on job finding rates that provide evidence on the existence of benefit exhaustion spikes. This indicates that the benefit exhaustion spike is more than a statistical artifact. As we discuss in more detail in the next section theoretical work based on non-stationary search theory explains the increase in the job finding rate towards benefit exhaustion (Mortensen 1977 and Van den Berg 1990). However, these studies do not explain why it falls again after expiration, which is needed to get a spike. ${ }^{2}$

Spikes in unemployment hazards are generally not accounted for in standard search models where agents are forward-looking. This follow trivially from the recursive nature of the solution to a Bellman equation. As a consequence, in order to account for spikes, it is necessary to amend the standard models. Our contribution to the literature is twofold. First, we provide a theoretical explanation for the existence of benefit exhaustion spikes, which are caused by delays in job acceptance. Our theoretical model suggests that spikes in job finding rates are more likely to occur for permanent jobs than for temporary jobs. Our theoretical model is not intended to replace existing theories of job search. We introduce an element in job acceptance behavior

\footnotetext{
2 Suggested explanations for the benefit spike include the strategic timing of job starting dates and implicit contracts between unemployed workers and their previous employers, in which the employers rehire the workers at about the time their benefits expire (Card and Levine 2000). However, these are notions rather than formalized theories. Also, the explanation provided by Card and Levine (2000) is very much related to the US labor market as in almost all European labor markets temporary layoffs do not occur.
} 
that allows us to explain a phenomenon that cannot be explained in traditional search theory. Second, we use a dataset on Slovenian unemployment spells to test this prediction. The information in this dataset is not restricted to leaving unemployment but includes information about job finding. In fact, we are able to distinguish between finding of permanent and temporary jobs. The existence of end-of-benefit spikes per se in Slovenia has been shown before but this was a by-product of an analysis on the impact of changes in potential benefit duration on job finding rates (Van Ours and Vodopivec (2006)). Here, we focus on the nature of the benefit exhaustion spikes. We show that indeed these spikes are more important in transitions from unemployment to permanent jobs than they are in transitions from unemployment to temporary jobs.

This paper is set-up as follows. In Sect. 2 we present our theoretical model in which individuals optimize the delay in job acceptance. In a stationary labor market the job finding rate equals the job offer arrival rate, but initially, because of the delay period no jobs are accepted. When an individual approaches benefit expiration the delay is reduced as no individual will want to accept a job offer beyond the point of benefit expiration. This delay behavior causes a spike at the point of benefit expiration. Delays in accepting job offers will not always occur. In case of temporary jobs delaying the start will not be acceptable to firms. Therefore, in the transition rate to temporary jobs an end of benefit spike is less likely to occur. In Sect. 3 we discuss our data and present some stylized facts. Using data from the Slovenian unemployment register we present "eyeball" evidence supporting our delay theory. Section 4 presents the results of our empirical analysis. We investigate whether job finding spikes at benefit exhaustion are smaller for temporary jobs. We find that this is indeed the case. Section 5 concludes.

\section{Optimal Delay in Job Acceptance: Theory}

We aim to explain the spike in the outflow from unemployment around the time the unemployment benefit expires. Therefore, we cannot use stationary models where unemployment benefits are paid irrespective of unemployment duration (or where the benefit entitlement is lost with an constant probability per period). We assume that for a duration $T$ the unemployed worker is entitled to unemployment benefits $b>0$. After expiration the benefits drop to a social assistance level $b_{s}<b$.

Two well known papers on nonstationarity in job search theory are Mortensen (1977) and Van den Berg (1990). In this setting, Van den Berg (1990) implies that the job acceptance probability increases with duration, jumps up at time $T$ and stays (that) high thereafter. Intuitively, if the benefit has dropped (to zero) the value of unemployment becomes so low that almost any job becomes acceptable. This reduces the reservation wage and hence increases the job acceptance rate. Thus, this analysis does not explain a spike in exit rates at $T$ as the exit rate does not fall after $T$.

Mortensen's (1977) model can explain a spike if one is willing to assume that income and leisure are substitutes. In that case, acceptance rates increase with duration and drop (discontinuously) at $T$ to a lower level. As the benefit drops to zero, leisure substitutes for income thereby reducing search effort (which takes up leisure 
time). In the case where leisure and income are complements (leisure is more enjoyable if there is more money to spend), the acceptance probability jumps up at $T$ and stays high thereafter. We find the assumption that income and leisure are complements more convincing since this is in line with all literature on the effects of the level of benefits on the job finding rate. ${ }^{3}$ Moreover, even in the case of substitutes, it is not clear why these effects would differ for different type of jobs.

There are also studies that use a static labor supply theory to motivate the existence of an end-of-benefit spike. Then, it is assumed that a new job can be found at any time (Meyer 1990; Moffitt and Nicholson 1982). At the time a worker loses his job he decides on consumption and the duration of unemployment subject to a budget constraint. At the expiration date $T$ the budget constraint is kinked and hence many indifference curves are tangent at the kink. Therefore, many individuals choose to leave unemployment at benefit expiration, which explains the spike in the outflow rate at $T$. However, this static model is less suitable as a framework to study benefit exhaustion spikes because it does not explain why the size of the spike depends on the type of job. As we show below in our empirical analysis benefit exhaustion spikes are larger for permanent than for temporary jobs. In fact, one can argue that in the Meyer (1990) and Moffitt and Nicholson (1982) framework to the extent that temporary jobs are easier to find than permanent jobs, this theory would predict a larger spike for temporary jobs. ${ }^{4}$

The two traditional theoretical explanations for the existence of a benefit exhaustion spike cannot explain why there would be a difference between spikes for temporary and permanent jobs. ${ }^{5}$ We propose a model where firms and workers are matched and then decide on the wage and the starting date of the job. We first describe the firm side of the story and then move on to the worker. Then we show how a delay in the starting date generates a spike in the outflow rate which is different in magnitude for temporary and permanent jobs.

\footnotetext{
3 Note that the case of income and leisure being substitutes would imply that an increase in unemployment benefits increases the job finding rate. A prediction that is clearly at odds with empirical research (see for example Atkinson and Micklewright 1991).

4 Note that the story in Meyer (1990) and Moffitt and Nicholson (1982) is not necessarily dynamically consistent. When a worker loses his job, a "holiday" of $T$ periods looks nice enough, but a week before $T$ he might like to re-optimize and extend his holiday. With such re-optimization it is not clear that many workers return to work at the kink in the budget constraint. In other words, how can the worker commit to starting a job at time $T$ ? Note also that in our model, the worker commits by signing a contract that specifies his starting date on the job.

5 A third explanation that is sometimes offered assumes heterogeneity in the dynamic search model. Suppose there are two groups of workers optimizing search intensity (and reservation wages) that face expiring benefits. One group has a very high offer arrival rate but faces a wage offer distribution with very low wages, so that they almost never accept job offers until benefits have expired after which they can quickly find a job. For the other group offers are rarer but wages are higher so their job finding rate is much smoother with only a small increase at the point of benefit exhaustion. In such a world a lot of individuals from the first group would exit at benefit exhaustion, leading to a spike at that point. Thus, the spike will be explained purely by heterogeneity not relying on strategic delays. Nevertheless, also this variant of the dynamic search model fails to explain why there would be a difference between transition to a permanent and temporary job. It is difficult to imagine that jobs with very low wages are also permanent jobs while jobs with high wages are temporary jobs.
} 


\subsection{Delay}

Consider a firm that has found a worker with productivity $q$. This worker yields a surplus to the firm equal to $s(q)$ with $s^{\prime}(q)>0$. Typically, $s(q)$ will be of the form $q-w(q)$ where the wage increases with $q$ but $w^{\prime}(q)<1$.

Let $l$ denote the length of the contract that the firm offers the worker and $\tau$ the period for which the worker would like to postpone actually starting to work. Then the discounted value for the firm of accepting this worker can be written as

$$
V(q, \tau)=\int_{0}^{\tau} 0 e^{-\rho t} d t+\int_{\tau}^{\tau+l} s(q) e^{-\rho t} d t=\frac{s(q)}{\rho} e^{-\rho \tau}\left(1-e^{-\rho l}\right)
$$

where $\rho$ denotes the discount rate. We assume here that the firm has work for a period $l$ independent of when this is done. ${ }^{6}$

Suppose the worker insists on a delay of $\tau$ periods, then this is only acceptable to the firm if $V(q, \tau)$ exceeds the outside option $O$ for the firm. One way to think of the outside option is that the firm can draw a new job applicant at $\operatorname{cost} c$. This will yield $O=-c+E(V(\tilde{q}, \tilde{\tau}))$ where the expectation is over the quality and required delay of the next worker. It turns out that we do not need to know much about the outside option $O$ to derive our results. Hence we do not introduce specific assumptions on how search for a new match takes place if negotiations with the currently matched employee break down.

For concreteness, we assume that the worker makes a take-it-or-leave-it offer to the firm about the starting date for the job. ${ }^{7}$ Further we assume that the wage cannot be varied with $\tau$. This can be justified in two ways. First, the wage may be given to the firm by an agreement with the labor unions. Second, if the wage is determined by bilateral bargaining between firm and employee, the employee may not be able to commit to a wage before starting the job. That is, if the worker agrees to a low wage (in return for a high $\tau$ ), he will renegotiate the wage once he starts the job. Hence the firm assumes that it will pay the employee this (renegotiated) wage anyway, independent of $\tau$. For our purposes we do not need to specify how the wage is determined exactly. We only assume $w \in\langle b, q\rangle$ where $b$ denotes the unemployment benefit level. Nash bargaining between worker and firm will give this result.

Further, we assume that the worker when asking for a delay of $\tau$ periods does not know $q .{ }^{8}$ Hence the probability that the firm rejects $\tau$ is given by

\footnotetext{
6 Alternatively, we can assume that the job involves seasonal work, that needs to be finished before a certain date $l$, say the end of the summer. In that case, the second integral is from $\tau$ to $l$. One can verify that similar results hold in this case. Clearly, also in this case $V_{\tau}^{\prime}<0$ : delaying the start of the job reduces the firm's profits as production and profit opportunities are destroyed.

7 Clearly, other assumptions would work here as well. The important point is that in negotiation with the firm the worker feels some restriction in delaying the start of the job out of fear that $V(q, \tau)<O$. See footnote 12 .

8 Alternatively, we can assume that the worker knows his own productivity $q$ but not the outside option $O$ of the firm.
} 


$$
\begin{aligned}
G(\tau, l) & =\operatorname{Prob}(V(q, \tau)<O) \\
& =\operatorname{Prob}\left(\frac{s(q)}{\rho} e^{-\rho \tau}\left(1-e^{-\rho l}\right)<O\right) \\
& =H\left(\frac{\rho O}{1-e^{-\rho l}} e^{\rho \tau}\right)
\end{aligned}
$$

where $H($.$) denotes the distribution function of s(q)$.

Hence we find 9

$$
\begin{aligned}
G_{\tau}^{\prime}(\tau, l) & =h\left(\frac{\rho O}{1-e^{-\rho l}} e^{\rho \tau}\right) \frac{\rho^{2} O}{1-e^{-\rho l}} e^{\rho \tau}>0 \\
G_{l}^{\prime}(\tau, l) & =-h\left(\left(\frac{\rho O}{1-e^{-\rho l}} e^{\rho \tau}\right) \frac{\rho^{2} O}{\left(1-e^{-\rho l}\right)^{2}} e^{\rho \tau}\right)<0
\end{aligned}
$$

Delaying the starting date of the job makes it more likely that the firm will look for another worker. Longer contracts make it more likely that a firm accepts a given delay $\tau$. We further assume that $h\left(\right.$.) is such that $G_{\tau l}^{\prime \prime}<0$ and $G_{\tau \tau}^{\prime \prime}>0$. For example, if $s(q)$ is uniformly distributed with a constant density $h$, we indeed have

$$
\begin{aligned}
G_{\tau l}^{\prime \prime} & =-h \frac{\rho^{3} O}{\left(1-e^{-\rho l}\right)^{2}} e^{\rho \tau}<0 \\
G_{\tau \tau}^{\prime \prime} & =h \frac{\rho^{3} O}{1-e^{-\rho l}} e^{\rho \tau}>0
\end{aligned}
$$

Now consider a worker who is matched with a firm. The worker's wage in this firm is given by $w .^{10}$ The worker proposes to delay the starting date by $\tau$ periods. Delay $\tau$ is given by the solution to

$$
\max _{t}(1-G(t, l)) V_{e}(t, l, \sigma)+G(t, l) V_{u}(\sigma)
$$

where $V_{e}$ denotes the value of having a job with the starting date postponed $t$ periods. We focus on the case where (temporary and permanent) job opportunities satisfy $V_{e}(t, l, \sigma)>V_{u}(\sigma)$. Hence the solution to Eq. (2) does not imply $G(\tau, l)=1$. The value $V_{e}$ satisfies

$$
\rho V_{e}(t, l, \sigma)=\int_{0}^{t} b e^{-\rho s} d s+\int_{t}^{l+t} w e^{-\rho s} d s+e^{-\rho(l+t)} \rho V_{u}(\sigma)+v(t, \sigma)
$$

\footnotetext{
9 To ease notation, we do not assume that the outside option depends on $l$. In fact, we could make this assumption. As long as the signs on the derivatives of $G$ below are unchanged, this has no effect on our analysis.

10 If the wage will be determined by (re)negotiation after the worker has actually started to work, the worker does not know $w$ exactly as he does not know $q$. In this case, $w$ denotes the expected wage.
} 
where the utility (in terms of leisure or home production) of delay is given by $v(t, \sigma){ }^{11}$ We assume $v_{t}^{\prime}, v_{\sigma}^{\prime}>0$ and $v_{t t}^{\prime \prime}<0, v_{t \sigma}^{\prime \prime}>0, v_{t t \sigma}^{\prime \prime \prime}<0$. In words, $\sigma$ determines the preference for delay. The higher $\sigma$ the higher the utility and marginal utility of delay. Finally, $v_{t \sigma}^{\prime \prime}$ falls with $t$. We refer to $\sigma$ as the value of leisure or home production.

After $l+t$ periods, the worker loses his job and is unemployed again (which gives him an expected discounted value $\rho V_{u}(\sigma)$ ). We assume that these discounted effects are rather small in the following sense:

$$
\begin{aligned}
\rho V_{e l}^{\prime} & =\rho e^{-\rho(l+t)}\left(\frac{w}{\rho}-\rho V_{u}(\sigma)\right)>0 \text { is close to zero } \\
\rho V_{e \sigma l}^{\prime \prime} & =-e^{-\rho(l+t)} \rho^{2} V_{u}^{\prime}(\sigma)<0 \text { is close to zero } \\
\rho V_{e l t}^{\prime \prime} & =-\rho^{2} e^{-\rho(l+t)}\left(\frac{w}{\rho}-\rho V_{u}(\sigma)\right)<0 \text { is close to zero } \\
\rho V_{e \sigma t}^{\prime \prime} & =-\rho^{2} e^{-\rho(l+t)} V_{u}^{\prime}(\sigma)+v_{t \sigma}^{\prime \prime}>0 \\
\rho V_{e \sigma t t}^{\prime \prime} & =\rho^{3} e^{-\rho(l+t)} V_{u}^{\prime}(\sigma)+v_{t t \sigma}^{\prime \prime \prime}<0
\end{aligned}
$$

Although this looks a bit technical, it simply says that the effects over $t+l$ periods are small and dominated by the direct effects of $v(t, \sigma)$. This seems a reasonable assumption.

The trade off described in Eq. (2) is between increasing the utility $V_{e}$ if the firm accepts the delay (which happens with probability $1-G$ ) and increasing the probability of being rejected in which case the worker continues to be unemployed with expected discounted value $V_{u}$. We assume that $d\left(V_{e}(t, l, \sigma)-V_{u}(\sigma)\right) / d \sigma<0$. In words, the higher the value of leisure or home production, the smaller the value of employment compared to unemployment. A search and matching framework will give this intuitive result. However, again, we do not need much structure on $V_{u}$ and $V_{e}$ and hence do not specify how they are determined exactly by the working of the labor market.

The first order condition for (an interior solution for the) optimal delay $\tau$ can be written as follows.

$$
G_{\tau}^{\prime}\left(V_{u}-V_{e}\right)+(1-G) V_{e \tau}^{\prime}=0
$$

where $V_{e \tau}^{\prime}=e^{-\rho \tau}(b-w)+\left(w-\rho V_{u}(\sigma)\right) e^{-\rho(l+\tau)}+v_{\tau}^{\prime}$. Note that $G_{\tau}^{\prime}, V_{e}-V_{u},(1-$ $G)>0$ imply that $V_{e \tau}^{\prime}>0$. Because delaying the starting date increases the risk of being rejected for the job, the worker asks for less than optimal delay in the sense that at the margin an increase in $\tau$ (still) raises $V_{e} \cdot{ }^{12}$

We can now derive the following result.

\footnotetext{
11 We assume that the worker signs a labor contract stipulating a starting day for the job. Hence we do not allow the worker to use the delay period to search for a better job. Allowing this would increase the size of the spike for the following two reasons. First, delay periods then become cumulative. Second, delay becomes more valuable for the worker giving a higher incentive to bargain for delays.

12 This also explains why we need to introduce a firm side to our story. If the employee could choose the delay $\tau$ without any restriction, he would choose $\tau$ such that $V_{e \tau}^{\prime}=0$. The solution to this equation only varies with $l$ because of the effect at $l+\tau$. Because of discounting, this effect is likely to be close to zero.
} 
Proposition 1 Assume the optimization problem given by (2) has an interior solution $\tau$. Then we find that

$$
\begin{aligned}
& \frac{d \tau}{d \sigma}>0 \\
& \frac{d \tau}{d l}>0
\end{aligned}
$$

Proof of Proposition 1 For an interior solution, the second order condition implies that

$$
|s o c|=-s o c=-G_{\tau \tau}^{\prime \prime}\left(V_{u}-V_{e}\right)+2 G_{\tau}^{\prime} V_{e \tau}^{\prime}-(1-G) V_{e \tau \tau}^{\prime \prime}>0
$$

The result then follows from the implicit function theorem:

$$
\begin{aligned}
& |\operatorname{soc}| \frac{d \tau}{d \sigma}=-G_{\tau}^{\prime} \frac{d\left(V_{e}-V_{u}\right)}{d \sigma}+(1-G) V_{e \tau \sigma}^{\prime \prime}>0 \\
& |\operatorname{soc}| \frac{d \tau}{d l}=-G_{\tau}^{\prime} V_{e l}^{\prime}-G_{\tau l}^{\prime \prime}\left(V_{e}-V_{u}\right)-G_{l}^{\prime} V_{e \tau}^{\prime}+(1-G) V_{e \tau l}^{\prime \prime}>0
\end{aligned}
$$

where the first inequality follows from $G_{\tau}^{\prime}>0, d\left(V_{e}-V_{u}\right) / d \sigma<0$ and assumption (7). The second inequality follows from $G_{\tau l}^{\prime \prime}, G_{l}^{\prime}<0, V_{e \tau}^{\prime}>0$ and assumptions (4) and (6).

Hence workers with a higher $\sigma$ postpone the starting date for a longer period. This happens for two reasons. First, they get a higher utility from delaying the starting date. Second, even if their proposal is rejected and they lose the job, this is not too bad for them as the loss $V_{e}-V_{u}$ is decreasing in $\sigma$.

Jobs with a longer tenure period lead to longer delays in starting the job. This happens for two related reasons. First, higher $l$ makes it more likely that the firm accepts the delay (that is, $G_{l}^{\prime}<0$ ). Second, increasing $\tau$ increases the probability that the firm rejects the employee's offer, but at a lower rate as $l$ increases $\left(G_{\tau l}^{\prime \prime}<0\right)$. There are two effects going in the opposite direction. First, higher $l$ implies that the job is worth more, as the drop in income from $w$ to the value of unemployment $\rho V_{u}$ happens further away in the future. This increases the loss if the employee's offer of $\tau$ is rejected $\left(V_{e l}^{\prime}>0\right)$ and may reduce $\tau$. Second, higher $l$ reduces the benefit of postponing the start of the job $\left(V_{e \tau l}^{\prime \prime}<0\right)$. This is again due to the effect at $\tau+l$. However, since these are effects in the future, discounting reduces the size of these effects. If the effects are small enough, they are dominated by the first two effects.

Finally, we can show the following.

Proposition 2 If $V_{e \tau \sigma}^{\prime \prime}, V_{e \tau l \sigma}^{\prime \prime \prime}, G_{\tau \tau}^{\prime \prime} d\left(V_{e}-V_{u}\right) / d \sigma$ are close to zero then

$$
\frac{d^{2} \tau}{d \sigma d l}<0
$$

Proof of Proposition 2 A sufficient condition for $\frac{d^{2} \tau}{d \sigma d l}<0$ is that $d\left(-G_{\tau}^{\prime} V_{e l}^{\prime}-\right.$ $\left.G_{\tau l}^{\prime \prime}\left(V_{e}-V_{u}\right)-G_{l}^{\prime} V_{e \tau}^{\prime}+(1-G) V_{e \tau l}^{\prime \prime}\right) / d \sigma<0$ while $d|\operatorname{soc}| / d \sigma>0$. Let us consider each condition in turn. First, 


$$
-G_{\tau}^{\prime} V_{e l \sigma}^{\prime \prime}+G_{\tau l}^{\prime \prime} \frac{d\left(V_{u}-V_{e}\right)}{d \sigma}-G_{l}^{\prime} V_{e \tau \sigma}^{\prime \prime}+(1-G) V_{e \tau l \sigma}^{\prime \prime \prime}<0
$$

because of assumptions (5) and $V_{e \tau \sigma}^{\prime \prime}, V_{e \tau l \sigma}^{\prime \prime \prime}$ close to zero together with $G_{\tau l}^{\prime \prime}<$ $0, d\left(V_{u}-V_{e}\right) / d \sigma>0$. Further,

$$
G_{\tau \tau}^{\prime \prime} \frac{d\left(V_{e}-V_{u}\right)}{d \sigma}+2 G_{\tau}^{\prime} V_{e \tau \sigma}^{\prime \prime}-(1-G) V_{e \tau \tau \sigma}^{\prime \prime \prime}>0
$$

as $G_{\tau \tau}^{\prime \prime} \frac{d\left(V_{e}-V_{u}\right)}{d \sigma}$ is assumed to be small, $G_{\tau}^{\prime}>0$ and assumptions (7) and (8).

Hence we see that higher $\sigma$ employees delay more (for each $l$ ). And for higher $\sigma$ the effect of $l$ on $\tau$ becomes smaller. If it is correct to assume that women have a higher value of home production (e.g. because they are not breadwinner), this result explains the findings below that women postpone more jobs (both temporary and permanent) and the differential effect between temporary and permanent jobs is smaller in terms of delay.

The conditions in the proposition are sufficient and not necessary. Although, the conditions are rather technical, they have the following interpretation. We know that $d \tau / d l>0$ and we want to understand when this derivative is smaller as $\sigma$ goes up. There are three effects going against this. First, $V_{e \tau \sigma}^{\prime \prime}>0$ : higher $\sigma$ leads to a higher marginal value of delay. This tends to raise $d \tau / d l$ as higher $l$ decreases the probability that the match is dissolved. Second $V_{e \tau l \sigma}^{\prime \prime \prime}>0$ : longer term contracts are more valuable to postpone as $\sigma$ goes up (that is, $V_{e \tau l}^{\prime \prime}<0$ increases with $\sigma$ ). This tends to raise $d \tau / d l$ as well. Third, if $G_{\tau \tau}^{\prime \prime}>0$ (which is the case above if the worker does not know $q$ and $H$ is uniform), an increase in $\sigma$ makes the problem less concave, as the loss $V_{e}-V_{u}$ falls with $\sigma$. This makes the agent's problem more elastic and tends to blow up $d \tau / d l$ as $\sigma$ increases. Hence we need to assume that these effects are relatively small.

\subsection{Spikes}

The delay in starting a job, described above, can lead to spikes in the unemployment outflow rate. Let $\alpha_{l}$ denote the arrival rate of jobs with duration $l$ for an unemployed worker searching for a job. As said, after $T$ periods the unemployment benefit drops from $b$ to $b_{s}<b$. Assume that this induces workers to accept a job without delay. ${ }^{13}$

Proposition 3 The outflow to l-jobs at $T$ is given by

$$
\int_{T-\tau_{l}}^{T} \alpha_{l} e^{-\sum_{j} \alpha_{j} t} d t
$$

where $\tau_{l}$ denotes the solution to Eq. (9).

\footnotetext{
13 This assumption simplifies the analysis but is by no means necessary. The relevant point is that the drop from $b$ to $b_{s}$ induces a mass of workers not to postpone the starting date beyond $T$. That is, we need to assume that there are workers who would postpone $\tau$ periods if the benefit level would remain at $b$ but who do not postpone beyond $T$ because of the drop in benefit level. This result is reminiscent of the Meyer (1990) and Moffitt and Nicholson (1982) kinked budget constraint result.
} 
Proof of Proposition 3 By assumption workers do not postpone starting a job found after $T$. Then $v_{t t}^{\prime \prime}<0$ implies that jobs found at time $t<T$ are never postponed past $T$ because $v_{t}^{\prime}(T-t, \sigma)<v_{t}^{\prime}(0, \sigma)$.

Hence the outflow at time $T$ is the "sum" (actually "integral") of workers matched with $l$-jobs from time $T-\tau_{l}$ till $T$. The stock of "free" workers at time $t$ that can be matched with an $l$-job is given by workers who up till then have not been matched with any job at all: $e^{-\sum_{j} \alpha_{j} t}$.

We get a spike because people matched over the interval $\left[T-\tau_{l}, T\right]$ all flow out of unemployment at the same time $T$. For given $\alpha_{l}$, this outflow is bigger, the longer the delay $\tau_{l}$. If the delay $\tau$ is zero for a certain type of job, there is-in principle-no spike.

Summarizing, the theory above leads to the following testable predictions. First, spikes are higher for permanent than for temporary jobs. If women have a higher value of home production $(\sigma)$ than men, we find that women delay the starting date longer than men (for both temporary and permanent jobs). Finally, the difference in spike between permanent and temporary jobs is smaller for women than for men.

\section{Data and Stylized Facts}

\subsection{Data}

Like OECD countries, Slovenia provides income support for the unemployed through a social insurance program that combines unemployment insurance and unemployment assistance. Benefits under employment insurance are earnings related, with the duration of entitlement contingent on work experience, with predetermined maximum and minimum levels. Unemployment assistance benefits are means-tested; they are offered to unemployed who exhausted their eligibility for unemployment insurance, and are for most workers substantially lower than unemployment insurance benefits.

Our empirical analysis is based on administrative records of unemployment spells, combined with selected information on formal employment spells. ${ }^{14}$ Included are all spells of unemployment benefit recipients which started between August 1, 1997 and July 31, 1998 and in the calendar year 1999 (with censoring on December 31, 2001). For each spell, the database contains starting and ending date of registered unemployment spell, destination of exit, and the information on the receipt of unemployment insurance benefits (starting and ending date of the eligibility and actual ending date of the receipt). Personal and family characteristics of recipients are also included. To improve the information about the end of unemployment spells, a separate source, work history data set for formal sector workers, was utilized. So, in our dataset the end of the unemployment spell is defined as the date at which an individual started working or left the unemployment register for other reasons. The destination "job" is defined by administrative records as exit to private or public employment, including self-employment. Other destinations include exits to active labor market programs,

\footnotetext{
14 The unemployment benefit system and the data are described in more detail in Van Ours and Vodopivec (2006, 2008).
} 
voluntary and involuntary removal from registration, and a miscellaneous category that includes maternity leave, military service and death. Here, we are only interested in job finding rates. If individuals left unemployment for other reasons their durations of unemployment are considered to be right-censored. The data we use are suitable to explore the existence of end of benefit spikes since our data do not only cover the period when workers were covered by unemployment benefits but also the period of transition from unemployment to employment after benefits expired. The date at which individuals started working on a job is not dependent on self-reporting of the unemployed workers but comes from employers. A unique feature of the Slovenian data is that at the start of the post-unemployment job its nature-temporary or permanent-is registered. Furthermore, we observe how long people stay in their jobs.

In our analysis we focus on individuals that were entitled to benefits for a maximum duration of 6, 9 or 12 months. For every unemployed worker after 3 months the replacement rate was reduced from $70 \%$ of the previous wage to $60 \%$ (subject to a minimum and maximum). Because the end of benefits effects for some workers coincides with a drop in the replacement rate for all workers, we ignore individuals with a potential benefit duration of 3 months. Slovenia reformed its unemployment benefits in 1998; the reform shortened the potential duration of benefits for most groups of workers. We use data from before and after the reform. The appendix provides more information about the data.

\subsection{Stylized Facts}

To illustrate the end of benefits effects, Figs. 1 and 2 show the relationship between job finding rates and months to benefit expiration for men and women, distinguished by potential benefit duration. ${ }^{15}$ There are clear spikes at benefit expiration for each of the three groups of workers. It is also clear that for temporary jobs there is a spike at benefit expiration, but in relative terms - compared to the job finding rates 2 or 3 months before benefit expiration - the spikes are considerably smaller than for the transition rate to permanent jobs.

To get a first impression whether indeed temporary jobs are less likely to generate benefit expiration spikes in the transition rate than permanent jobs, we did some simple calculations. For each group of workers with the same potential benefit duration we divided the permanent job finding rate in the month of benefit expiration by this rate in the month prior to that. We did the same for the temporary job finding rate. The first two columns of Table 1 show the outcomes of these calculations. Indeed, whereas for males the average relative spike for permanent jobs is 3.37 , it is only 1.43 for temporary jobs. For females the average relative spike for permanent jobs is 3.91 , while for temporary jobs it is 1.64 .

\footnotetext{
15 The job finding rates are calculated on a monthly basis taking right-censored durations into account. The same holds for the job separation rates in Fig. 3. Note that we can identify the spikes because they occur at different unemployment durations for different groups of workers. Otherwise, we could not distinguish the spike from the effect of duration dependence.
} 


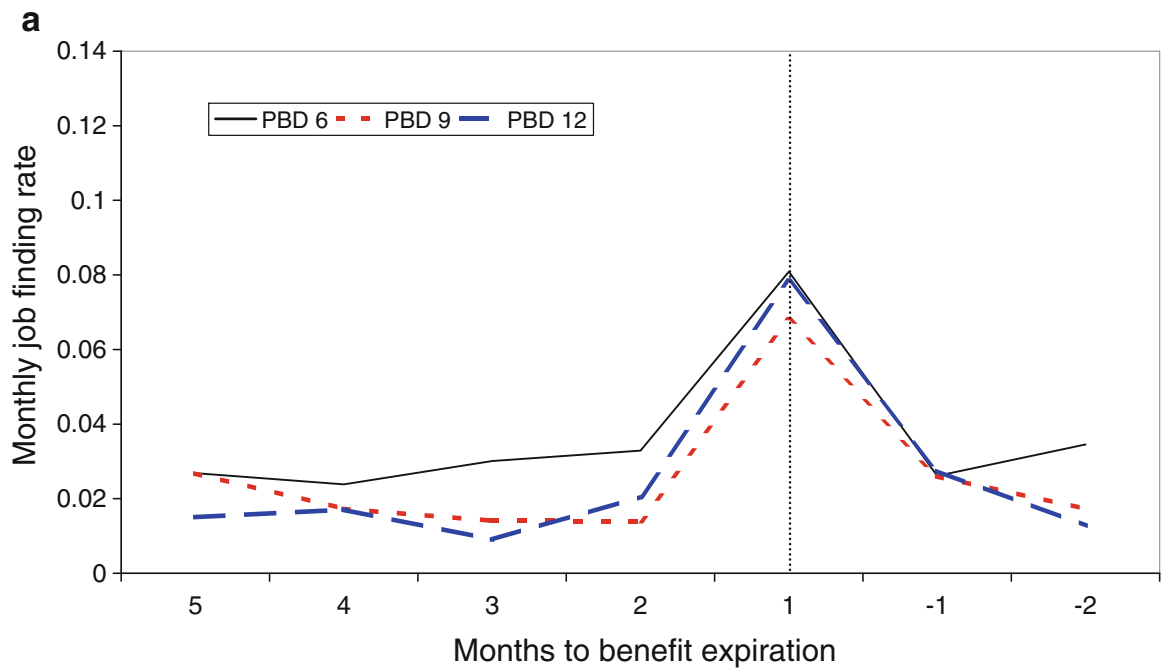

b

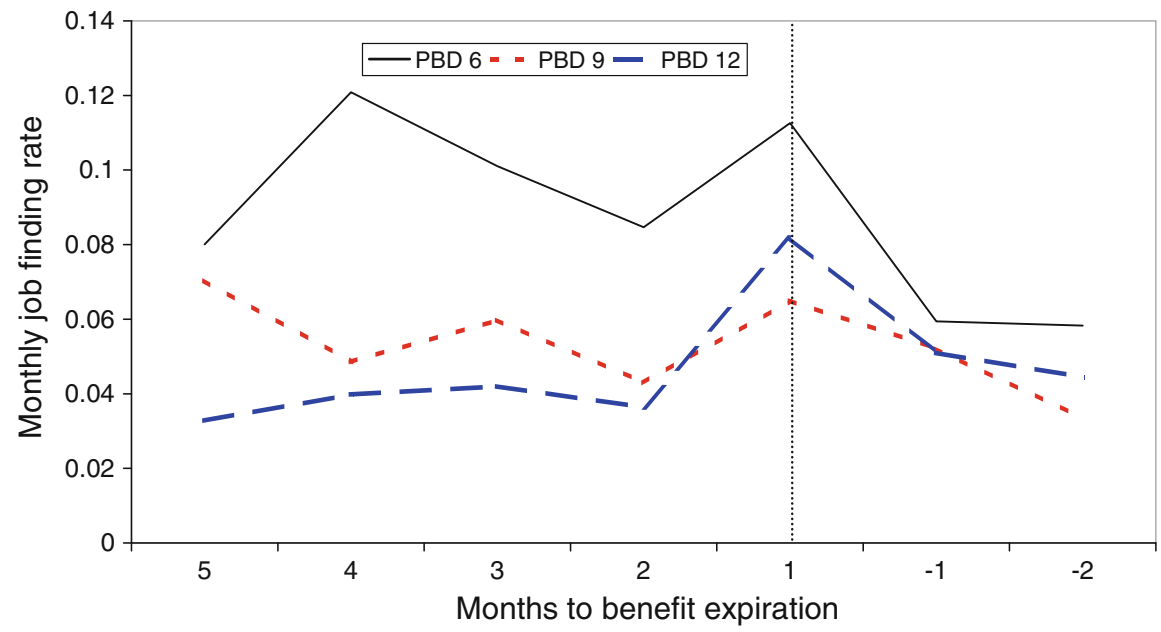

Fig. 1 Job finding rates close to benefit expiration—-men: a permanent jobs, $\mathbf{b}$ temporary jobs

The top part of Fig. 3 shows job separation rates for men, distinguished between temporary jobs and permanent jobs. As was to be expected, the job separation rates from temporary jobs are much higher as the job separation rates from permanent jobs. There is a large spike in the job separation rate for temporary jobs at 9 months indicating the importance of fixed-term contracts of that particular duration. Similarly there are also spikes at 3,6 and 12 months. The bottom part of Fig. 3 shows the job separation rates for women which are very similar to those of men. Clearly, individuals on permanent jobs do not leave their jobs quickly; 12 months after starting on a permanent job $94 \%$ the men and $95 \%$ of the women are still employed. From the workers on temporary jobs after 1 year $59 \%$ of the men and $66 \%$ of the women is still employed. 


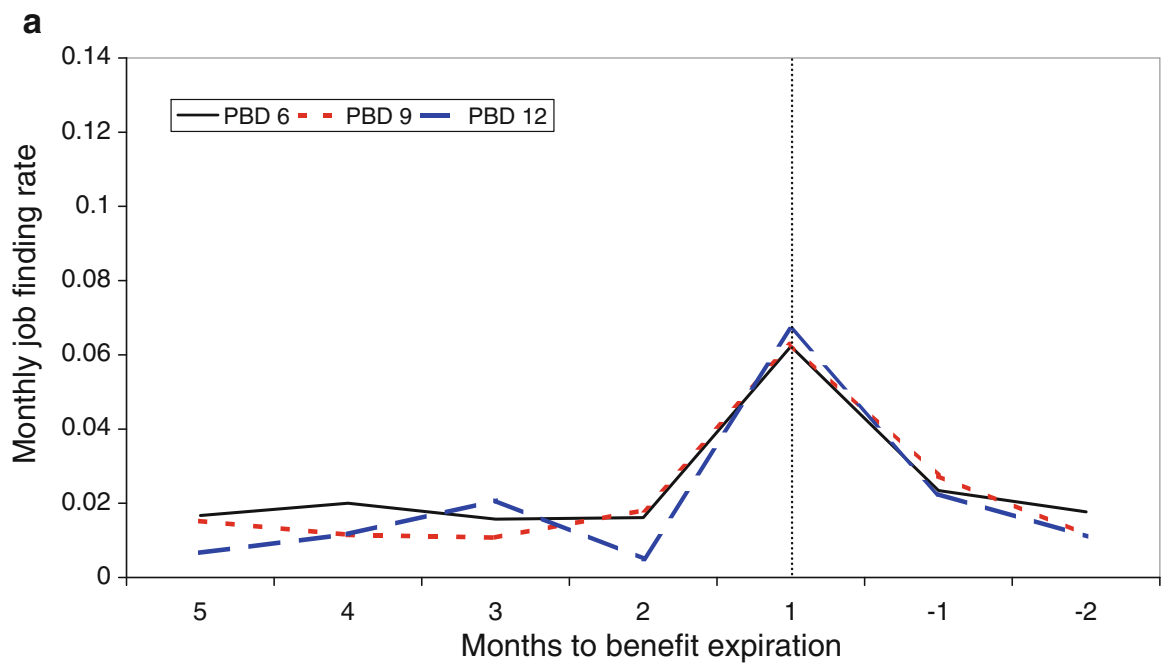

b

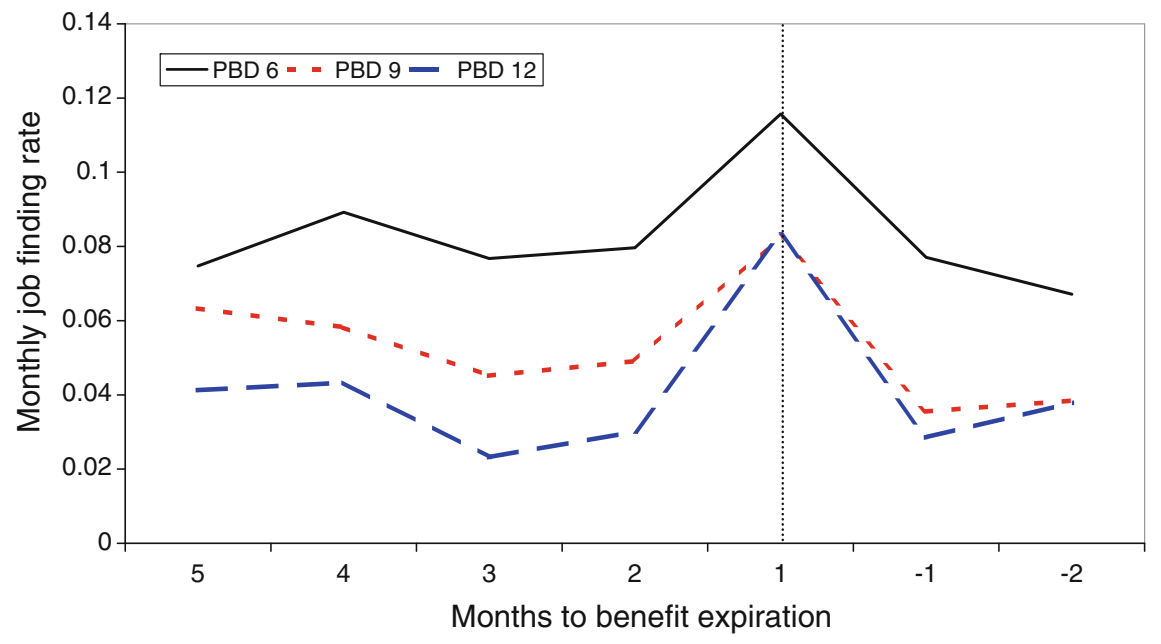

Fig. 2 Job finding rates close to benefit expiration-women: a permanent jobs, b temporary jobs

\section{Empirical Analysis}

\subsection{Job Finding Rates}

The use of hazard rate models and the data with individuals facing different potential benefit durations allow us to identify the end-of-benefit spikes. We distinguish between transition rates to permanent and to temporary jobs and start with a set-up that is in line with our theoretical model. The rate at which individuals find a permanent or a temporary job at unemployment duration $t$ conditional on observed characteristics $x$ and unobserved characteristics $u$ is assumed to have the following specification 
Table 1 Spikes by potential benefit duration

\begin{tabular}{|c|c|c|c|c|}
\hline \multirow[t]{2}{*}{ PBD (months) } & \multirow{2}{*}{$\begin{array}{l}\text { Permanent } \\
\text { jobs } \\
\text { (1) }\end{array}$} & \multicolumn{3}{|c|}{ Temporary jobs } \\
\hline & & $\begin{array}{l}\text { Total } \\
\text { (2) }\end{array}$ & $\begin{array}{l}<1 \text { year } \\
\text { (3) }\end{array}$ & $\begin{array}{l}\geq 1 \text { year } \\
\text { (4) }\end{array}$ \\
\hline \multicolumn{5}{|l|}{ Males } \\
\hline 6 & 2.68 & 1.31 & 0.79 & 1.76 \\
\hline 9 & 7.14 & 1.58 & 1.39 & 1.75 \\
\hline 12 & 2.88 & 1.80 & 1.18 & 2.36 \\
\hline Average & 3.37 & 1.43 & 0.98 & 1.82 \\
\hline \multicolumn{5}{|l|}{ Females } \\
\hline 6 & 3.78 & 1.39 & 1.27 & 1.47 \\
\hline 9 & 2.83 & 1.71 & 1.59 & 1.76 \\
\hline 12 & 10.15 & 3.18 & 3.54 & 3.04 \\
\hline Average & 3.91 & 1.64 & 1.50 & 1.71 \\
\hline
\end{tabular}

Note that the average relative spike is calculated as the job finding rate in the month of benefit expiration divided by the job finding rate in the month previous to that. Also note that the distinction between the duration of temporary jobs is based on ex post information

$$
\theta_{i}\left(t \mid x, u_{i}\right)=\lambda_{i}(t) \exp \left(x^{\prime} \beta_{i}+u_{i}\right) \text { for } i=p, n
$$

where $i$ indicates the type of job ( $p=$ permanent, $n=$ temporary), $\beta$ is a vector of parameters and $\lambda$ represents individual duration dependence, which is modeled in a flexible way by using step functions:

$$
\lambda_{i}(t)=\exp \left(\Sigma_{k} \mu_{i, k} I_{k}(t)+\delta_{i} I_{s}(t)\right) \text { for } i=p, n
$$

where $k(=1, \ldots, 4)$ is a subscript for duration interval. We distinguish four intervals, monthly for the first 3 months, and the fourth interval larger than 3 months. For reasons of normalization we impose $\mu_{i, 4}=0$. If a period of delay exists, in the job finding rate concerning permanent jobs at least the initial $\mu$-parameters should be smaller than zero. For temporary jobs this should not be the case. Furthermore, $I_{s}$ is an indicator for the month of benefit expiration $(s=6,9,12)$. The $\mu$-parameters measure the pattern of duration dependence, and $\delta$ indicates the size of the spike in the month of benefit expiration. If the period of delay exists we expect a spike to be present in the job finding rate for permanent jobs, while such a spike should be less important in the job finding rate for temporary jobs.

The conditional density function of the completed unemployment duration $t_{i}$ that ended in a transition towards a job of type $i$ can be written as

$$
f\left(t_{i} \mid x, u_{i}\right)=\theta_{i}\left(t_{i} \mid x, u_{i}\right) \exp \left(-\int_{0}^{t_{i}}\left(\theta_{p}\left(s \mid x, u_{p}\right)+\theta_{n}\left(s \mid x, u_{n}\right)\right) d s\right) \text { for } i=p, n
$$


a

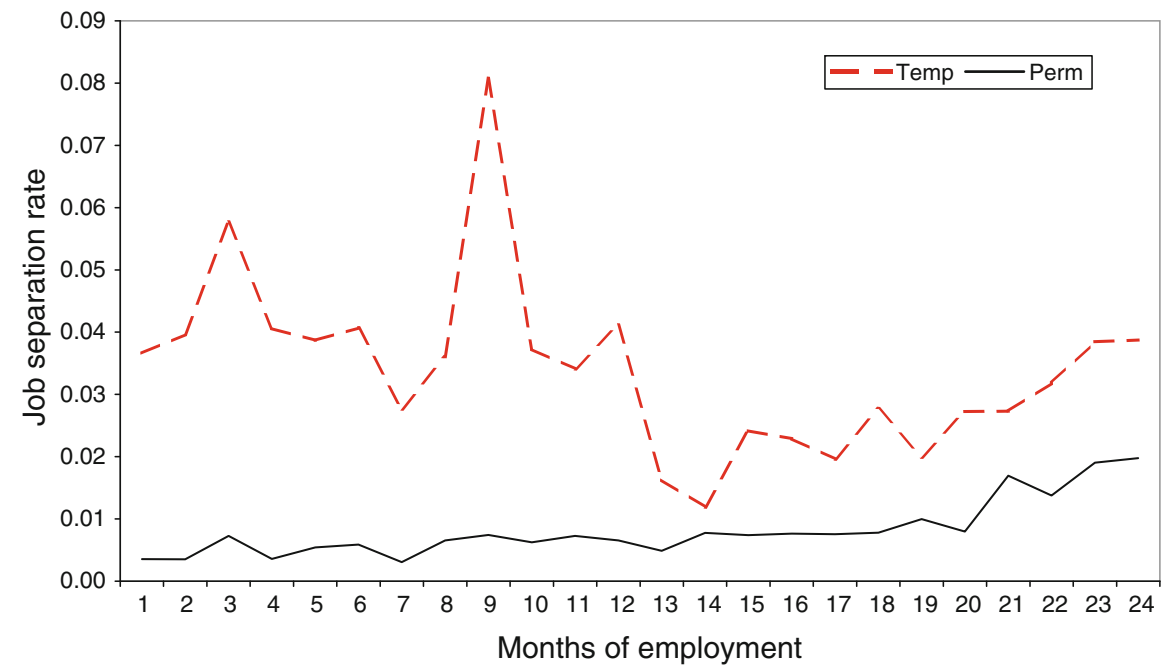

b

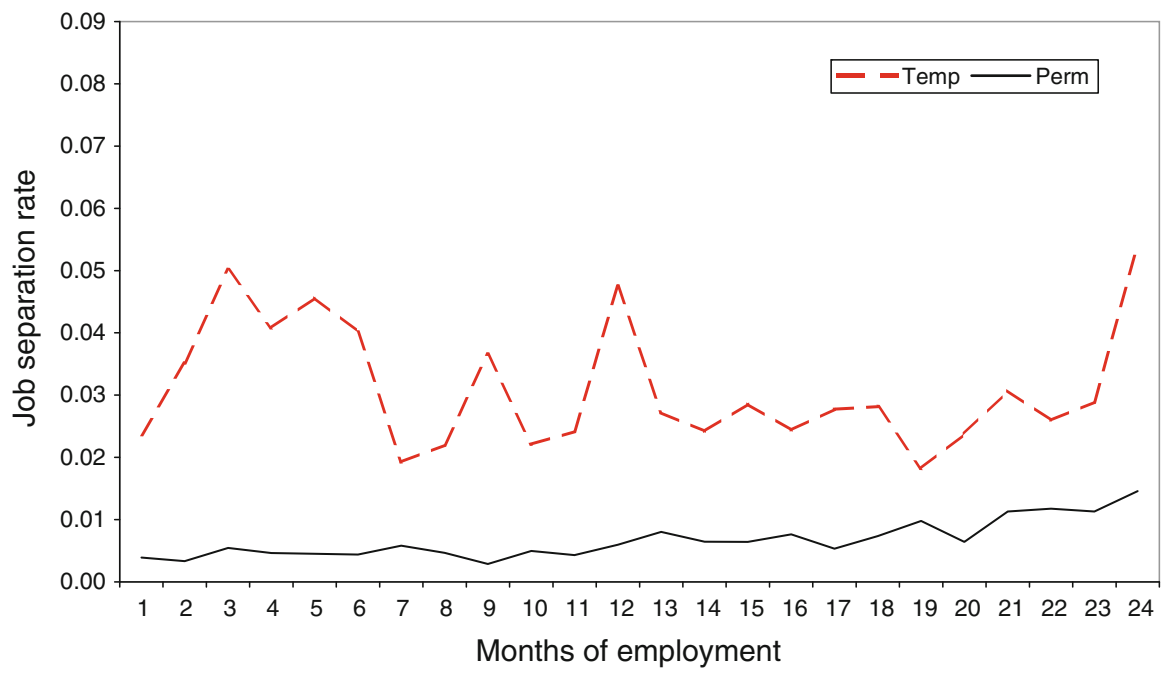

Fig. 3 Job separation rates - men (a) and women (b)

We assume that the unobservables in both job finding rates are from discrete distributions with two points of support, which we assume to be perfectly correlated. ${ }^{16}$ Then, the joint distribution also has two points of support, $p_{1}$ and $p_{2}$

$$
\operatorname{Pr}\left(u_{p}=u_{p, a}, u_{n}=u_{n, a}\right)=p_{1} \quad \operatorname{Pr}\left(u_{p}=u_{p, b}, u_{n}=u_{n, b}\right)=p_{2}
$$

\footnotetext{
16 We investigated whether it was possible to estimate an extended distribution of unobserved heterogeneity but we were not able to identify a third mass-point.
} 
Because the hazard rates also contain constant terms, we normalize $u_{p, a}=u_{n, a}=0$. The discrete distribution is supposed to have a logit specification with $p_{1}=\frac{\exp (\alpha)}{1+\exp (\alpha)}$ and $p_{2}=\frac{1}{1+\exp (\alpha)}$. We remove the unobserved components by taking expectations:

$$
f\left(t_{p}, t_{n} \mid x\right)=E_{u_{p}} E_{u_{n}}\left[f_{p}\left(t_{p} \mid x, u_{p}\right) \cdot f_{n}\left(t_{n} \mid x, u_{n}\right)\right]
$$

The parameters are estimated with the method of maximum likelihood, taking into account that some durations are right-censored.

The analyses are done separately for males and females to account for possible differences in labor market behavior. In addition to this distinction by gender the effect of the following personal characteristics are taken into account: age, education, family situation, health, and calendar period of inflow into unemployment (see the appendix for details).

Panel $a$ of Table 2 shows the parameter estimates for the baseline model. Age has a negative effect on all job findings rates. Education has a positive effect on the job finding rate concerning permanent jobs but has no effect on the rate by which individuals find temporary jobs; with the exception of higher educated males who have a smaller transition rate to temporary jobs. Family conditions do not affect the transition rate to temporary jobs, but the effect for permanent jobs differs for males and females. Concerning permanent jobs, males who have dependent family members have a higher job finding rate than males who do not, but females with dependent family members have a lower job finding rate than other females. Bad health reduces all job finding rates substantially.

There is also evidence of unobservables affecting the job finding rates. Conditional on the observable characteristics and the elapsed duration of unemployment there is a group of $87 \%$ of the males that has a high job finding rate both to permanent and temporary jobs, while the remaining $13 \%$ has substantially lower job finding rates. For women these percentages are 83 for the group with high job finding rates and 17 for the group with low job finding rates.

The pattern of duration dependence is different for permanent jobs and temporary jobs. For permanent jobs the job finding rate is low in the first months of the unemployment spell, which is support for the existence of a delay period. The transition rate to temporary jobs in the first months is higher than later on.

The most important parameter estimates refer to the spike in job findings rates at benefit exhaustion. This spike is identified by comparing the job finding rate in the month of benefit expiration for some groups of workers with the identical non-expiration month for other groups of workers. It appears that there are substantial spikes. The job finding rate concerning permanent jobs in a month of benefit expiration is about 3 times as high for men and 3.7 times as high for women as in the same month without benefit expiration. Also in the transition rates to temporary jobs we find spikes, which are about $50 \%$ (men) to $75 \%$ (women) higher than regular job finding rates. The difference between the spikes in the job finding rates between permanent and temporary jobs supports our theoretical model. Apparently for temporary jobs delaying acceptance is more difficult. Hence the spike is smaller.

Panel $b$ of Table 2 shows the parameter estimates for the spike if we impose that there is no duration dependence. There is a clear drop in the log-likelihood value from 
Table 2 Parameter estimates job finding rates-baseline model

\begin{tabular}{|c|c|c|c|c|}
\hline & \multicolumn{2}{|l|}{ Males } & \multicolumn{2}{|l|}{ Females } \\
\hline & Permanent job & Temporary job & Permanent job & Temporary job \\
\hline \multicolumn{5}{|c|}{ (a) Baseline model } \\
\hline Age/10 & $-0.53(5.3)^{* *}$ & $-0.46(7.9)^{* *}$ & $-0.35(3.3)^{* *}$ & $-0.50(8.9)^{* *}$ \\
\hline Educ2 & $0.11(0.5)$ & $-0.03(0.3)$ & $1.19(2.5)^{* *}$ & $-0.02(0.2)$ \\
\hline Educ3 & $0.55(2.7)^{* *}$ & $-0.13(1.4)$ & $1.64(3.5)^{* *}$ & $-0.15(1.3)$ \\
\hline Educ4 & $0.87(4.2)^{* *}$ & $-0.44(4.5)^{* *}$ & $2.13(4.6)^{* *}$ & $-0.13(1.2)$ \\
\hline Family1 & $0.12(1.4)$ & $-0.00(0.0)$ & $-0.26(2.8)^{* *}$ & $0.06(1.0)$ \\
\hline Family2 & $0.16(2.0)^{*}$ & $0.01(0.2)$ & $-0.24(2.8)^{* *}$ & $0.01(0.3)$ \\
\hline Bad health & $-2.25(12.5)^{* *}$ & $-1.81(21.7) * *$ & $-2.21(8.8)^{* *}$ & $-2.09(19.0)^{* *}$ \\
\hline Group 2 & $0.05(0.4)$ & $0.15(1.7)^{*}$ & $0.26(2.0)^{* * *}$ & $0.03(0.3)$ \\
\hline Group 3 & $0.19(1.3)$ & $0.27(2.9)^{* *}$ & $0.17(1.2)$ & $0.24(2.8) * *$ \\
\hline Group 4 & $0.09(0.6)$ & $0.23(2.4)^{* *}$ & $0.26(1.7)^{*}$ & $0.08(0.8)$ \\
\hline Group 5 & $0.54(3.3) * *$ & $0.42(4.2) * *$ & $0.29(1.8)^{*}$ & $0.47(5.1)^{* *}$ \\
\hline Group 6 & $0.71(3.8)^{* * *}$ & $0.56(4.8)^{* *}$ & $0.51(2.6)^{* *}$ & $0.73(6.6)^{* *}$ \\
\hline Constant & $-6.00(17.6)^{* *}$ & $-4.46(22.8)^{* *}$ & $-8.15(14.8)^{* *}$ & $-4.62(23.0)^{* *}$ \\
\hline \multicolumn{5}{|l|}{ First months } \\
\hline Month 1 & $-0.63(5.0)^{* *}$ & $0.17(2.9)^{* *}$ & $-0.21(1.7)^{*}$ & $0.32(5.8) * *$ \\
\hline Month 2 & $-0.39(3.2)^{* *}$ & $0.12(2.0)^{* *}$ & $-0.12(1.0)$ & $0.08(1.2)$ \\
\hline Month 3 & $-0.29(2.4)^{* *}$ & $0.45(8.0)^{* *}$ & $-0.07(0.6)$ & $0.21(3.6)^{* *}$ \\
\hline Spike & $1.09(11.8)^{* *}$ & $0.42(5.5)^{* *}$ & $1.32(14.6)^{* * *}$ & $0.55(8.4)^{* *}$ \\
\hline \multicolumn{5}{|c|}{ Unobs. heterogeneity } \\
\hline Masspoint 2 & $-7.66(17.3)^{* *}$ & $-9.91(2.4)^{* *}$ & $-9.99(15.2)^{* *}$ & $-\infty$ \\
\hline$\alpha$ & $1.89(12.9)^{* *}$ & & $1.61(19.1)^{* *}$ & \\
\hline \multicolumn{5}{|c|}{ (b) No initial drop } \\
\hline Spike & $1.30(14.7)^{* *}$ & $0.35(4.6)^{* *}$ & $1.39(16.0)^{* *}$ & $0.47(7.3)^{* *}$ \\
\hline Loglikelihood & $29,331.9$ & & $32,168.1$ & \\
\hline \multicolumn{5}{|c|}{ (c) Extended model } \\
\hline Spike & $1.63(11.3)^{* *}$ & $0.59(6.1)^{* *}$ & $1.60(11.6)^{* *}$ & $0.66(7.8)^{* *}$ \\
\hline Loglikelihood & $29,216.3$ & & $32,140.3$ & \\
\hline Observations & 5,583 & & 6,478 & \\
\hline
\end{tabular}

Absolute $t$ statistics in parentheses; a ** (*) indicates significance at a $95 \%(90 \%)$ level

which we conclude that we cannot reject the pattern of duration dependence found in panel $a$.

Panel $c$ of Table 2 shows the parameter estimates for the spike if we introduce a very flexible specification of duration dependence with monthly intervals for the first 6 months, and after that the intervals 6-9, 10-12, 13-18 months and 18+ months. Furthermore, we introduce an indicator for benefit expiration because individuals may 
increase their search intensity after benefits have expired. ${ }^{17}$ As shown the spike in the job finding rate for permanent jobs is substantially larger than for temporary jobs. However, as in the baseline estimates we cannot ignore the existence of a benefit spike in the exits to temporary jobs.

\subsection{Job Separation Rates}

The type of post-unemployment jobs is registered as being permanent or fixed-term, which we interpret as being temporary. The nature of the job is labeled at the start, but permanent jobs may not last long and temporary contracts may be extended so that temporary jobs may last quite some time.

To investigate the determinants of job separations we estimate a proportional hazard model where the job separation rate from jobs of type $i$ at employment duration $t$ conditional on observed variables $x$ and unobserved characteristics $v$

$$
\theta_{i}^{s}(t \mid x)=\lambda_{i}^{s}(t) \exp \left(x^{\prime} \beta_{i}^{s}+z^{\prime} \gamma_{i}^{s}+v_{i}\right) \quad \text { for } i=p, n
$$

where $z$ is a vector of variables that indicate when the unemployed left unemployment - the month of unemployment and whether or not it was the last month of benefits before expiration. Furthermore, $\beta^{s}$ and $\gamma^{s}$ are vectors of parameters, and $\lambda^{s}$ represents individual duration dependence, which is again modeled in a flexible way by using step functions:

$$
\lambda_{i}^{s}(t)=\exp \left(\Sigma_{k} \mu_{i, k}^{s} I_{k}(t)\right)
$$

where $k(=1, \ldots, 10)$ is a subscript for duration interval and we consider the following ten intervals: 1, 2, 3, 4, 5, 6, 7-9, 10-12, 13-18, 18+. For reasons of normalization we impose $\mu_{i, 1}^{s}=0$. The conditional density function of completed job durations and the likelihood function are set-up as before. As with the job finding rates also for the job separation rates we assume that the unobservables are from discrete distributions with two points of support, which we assume to be perfectly correlated.

The parameter estimates are presented in Table 3. The duration of permanent jobs for males is affected by their age, education and health. Older, lower educated males with bad health have a higher job separation rates than their counterparts. For females the separation rate form permanent jobs is not affected by any personal characteristic. The duration of temporary jobs is only affected by age and family situation. Older individuals are more likely to loose their temporary job quickly. The effect of family situation differs for males and females. Whereas males with 1 dependent family member are more likely to loose their temporary job, females with 2 or more dependent family members are less likely to loose their job.

Remarkably, for permanent jobs the duration doesn't depend on the previous unemployment spell. It doesn't matter whether an unemployed worker finds a permanent

\footnotetext{
17 Note also that we can still identify $\delta$ because the spike occurs at different unemployment durations. If not, we could not distinguish the spike from the effect of duration dependence.
} 
Table 3 Parameter estimates job separation rates-baseline model

\begin{tabular}{|c|c|c|c|c|}
\hline & \multicolumn{2}{|l|}{ Males } & \multicolumn{2}{|l|}{ Females } \\
\hline & Permanent job & Temporary job & Permanent job & Temporary job \\
\hline Age/10 & $0.48(3.4)^{* *}$ & $0.36(4.3)^{* *}$ & $0.15(0.9)$ & $0.31(3.9)^{* *}$ \\
\hline Educ2 & $-0.41(1.4)$ & $0.23(1.9)^{*}$ & $-0.44(0.5)$ & $-0.13(0.8)$ \\
\hline Educ3 & $-0.72(2.6) * *$ & $0.04(0.3)$ & $-0.60(0.7)$ & $-0.10(0.7)$ \\
\hline Educ4 & $-0.96(3.3)^{* *}$ & $0.01(0.1)$ & $-0.75(0.9)$ & $-0.22(1.3)$ \\
\hline Family1 & $-0.15(1.0)$ & $0.25(3.3)^{* *}$ & $0.13(0.9)$ & $-0.02(0.2)$ \\
\hline Family2 & $-0.08(0.6)$ & $0.01(0.1)$ & $-0.13(0.9)$ & $-0.11(1.7)^{*}$ \\
\hline Bad health & $0.56(2.0)^{* *}$ & $0.19(1.6)$ & $0.58(1.6)$ & $0.17(0.9)$ \\
\hline Month 2 & $0.01(0.0)$ & $0.12(1.0)$ & $-0.49(1.1)$ & $0.23(1.8)^{*}$ \\
\hline Month 3 & $0.50(1.4)$ & $0.52(4.7)^{* *}$ & $0.34(1.0)$ & $0.64(5.1)^{* *}$ \\
\hline Month 4 & $-0.38(0.8)$ & $0.10(0.8)$ & $-0.45(1.0)$ & $0.51(3.9)^{* *}$ \\
\hline Month 5 & $-0.03(0.1)$ & $0.21(1.7)^{*}$ & $-0.59(1.3)$ & $0.88(7.2)^{* *}$ \\
\hline Month 6 & $-0.18(0.4)$ & $0.25(2.0)^{* *}$ & $-0.09(0.2)$ & $0.44(3.2)^{* *}$ \\
\hline Month 7-9 & $0.14(0.4)$ & $0.41(3.9)^{* *}$ & $-0.06(0.2)$ & $0.07(0.6)$ \\
\hline Month 10-12 & $0.15(0.5)$ & $0.29(2.6)^{* *}$ & $-0.13(0.4)$ & $0.31(2.4)^{* *}$ \\
\hline Month 13-18 & $-0.09(0.3)$ & $-0.36(3.0)^{* *}$ & $0.02(0.1)$ & $0.02(1.2)$ \\
\hline Month $18+$ & $-0.05(0.2)$ & $-0.39(3.0)^{* *}$ & $-0.21(0.7)$ & $-0.19(1.3)$ \\
\hline After expiration & $-0.10(0.3)$ & $-0.09(0.6)$ & $-0.08(0.3)$ & $0.32(2.1)^{* *}$ \\
\hline \multicolumn{5}{|c|}{ Left unemployment } \\
\hline Month 2 & $0.06(0.2)$ & $-0.67(6.8)^{* *}$ & $-0.07(0.3)$ & $-0.47(4.3)^{* *}$ \\
\hline Month 3 & $0.19(0.8)$ & $-0.53(5.3)^{* *}$ & $0.12(0.4)$ & $-0.24(2.1)^{* *}$ \\
\hline Month 4 & $0.09(0.4)$ & $-0.67(6.0)^{* *}$ & $0.06(0.2)$ & $-0.39(3.2)^{* *}$ \\
\hline Month 5 & $0.05(0.2)$ & $-0.43(3.7)^{* *}$ & $0.32(1.1)$ & $-0.27(2.1)^{* *}$ \\
\hline Month 6 & $-0.42(1.3)$ & $-0.76(5.0)^{* *}$ & $-0.07(0.2)$ & $-0.52(3.6)^{* *}$ \\
\hline Month 7-9 & $-0.26(0.9)$ & $-0.62(4.9)^{* *}$ & $0.18(0.6)$ & $-0.59(4.5)^{* *}$ \\
\hline Month 10-12 & $-0.06(0.2)$ & $-0.61(3.6)^{* *}$ & $-0.02(0.1)$ & $-0.72(4.1)^{* *}$ \\
\hline Month 13-18 & $0.07(0.2)$ & $-0.58(2.8)^{* *}$ & $0.07(0.2)$ & $-0.56(2.9)^{* *}$ \\
\hline Month 18+ & $-0.11(0.2)$ & $-0.47(2.0)^{* *}$ & $0.39(0.9)$ & $-0.59(2.9)^{* *}$ \\
\hline In "spike" month & $-0.35(2.3)^{* *}$ & $-0.26(2.0)^{* *}$ & $0.08(0.3)$ & $0.01(0.1)$ \\
\hline Constant & $-7.87(13.5)^{* *}$ & $-7.05(24.8)^{* *}$ & $-7.03(6.8)^{* *}$ & $-6.95(24.2)^{*}$ \\
\hline Masspoint 2 & - & $-\infty$ & - & $-\infty$ \\
\hline$\alpha$ & - & $1.50(11.4)^{* *}$ & - & $1.41(6.9)^{* *}$ \\
\hline Observations & 1,027 & 2,973 & 939 & 3,307 \\
\hline
\end{tabular}

Not reported are the parameter estimates related dummy variables for each of the 6 groups of unemployed; absolute $t$ statistics in parentheses; a ** (*) indicates significance at a $95 \%(90 \%)$ level

job early on in the unemployment spell or much later, the job separation rate is equally high. For females it is irrelevant whether or not the unemployed worker finds a permanent job in the month of benefit expiration. Apparently, it is not just the "strong" worker that postpones her start until the moment at which benefits expire. This is support for our hypothesis that it is the delay in acceptance which is driving the benefit 
spike. For temporary jobs the previous unemployment spell has some importance. Especially workers that find a temporary job in the first month of their unemployment spell are more likely to loose this job quickly. Males that find a job in the month of benefit expiration are less likely to loose this job quickly. This could point at reverse causality. Males that have the opportunity to start on a long term job are more likely to postpone this start until the month of benefit expiration. Again, this would be support for our delay theory.

Concerning unobserved heterogeneity the results are different for permanent jobs and temporary jobs. Whereas for permanent jobs we found no indication of unobserved heterogeneity, for temporary jobs we do find that unobserved heterogeneity affects the separation rate. Most temporary jobs exist only shortly but there are also temporary jobs which last very long. Conditional on the observed characteristics, the unemployment history and the duration of the employment spell there is a group of temporary jobs of $82 \%$ for males ( $80 \%$ for females) that last short, while the complementary $18 \%$ (20\% for females) lasts very long.

\subsection{Temporary Jobs}

\subsubsection{Finding and Separating}

The relationship between the benefit expiration spike and the duration of the first job may be affected by correlation between unobservables in the job finding rate and the job separation rate. To investigate this we estimate a bivariate duration model with correlated error terms. We do the estimates for temporary jobs, separately for males and females.

In both the job finding rate for temporary jobs and the job separation rate from temporary jobs we introduce unobserved heterogeneity. Both rates are now specified as

$$
\begin{aligned}
& \theta_{n}\left(t \mid x, u_{n}\right)=\lambda(t) \exp \left(x^{\prime} \beta_{n}+u_{n}\right) \\
& \theta_{n}^{s}\left(t \mid x, u_{n}^{s}\right)=\lambda^{s}(t) \exp \left(x^{\prime} \beta_{n}^{s}+z^{\prime} \gamma^{s}+u_{n}^{s}\right)
\end{aligned}
$$

where $u_{n}$ and $u_{n}^{s}$ represent unobserved heterogeneity. As before, we assume that the unobservables in both the job finding rate and the job separation rate are from discrete distributions with two points of support which are integrated out of the likelihood specification.

The main parameter estimates are summarized in Table 4. As shown the second mass points are negative for the job finding rate and positive for the job separation rate. Conditional on the observed characteristics and the elapsed durations of the unemployment and employment spells individuals that have a low job finding rate also have a high job separation rate. If it takes a long time to find a job, the job found doesn't last very long. However, the size of the benefit exhaustion spikes are not influenced by the introduction of unobserved heterogeneity. They are almost identical to the ones presented in Table 2. 
Table 4 Parameter estimates job finding and separation rates-temporary jobs

\begin{tabular}{lll}
\hline & Males & Females \\
\hline 2nd masspoint & & \\
Job finding & $-0.76(2.9)^{* *}$ & $-0.95(2.3)^{* *}$ \\
Job separation & $2.56(14.6)^{* *}$ & $2.47(4.7)^{* *}$ \\
Spike & $0.56(6.0)^{* *}$ & $0.67(7.7)^{* *}$ \\
$\alpha$ & $-1.02(4.5)^{* *}$ & $-1.39(2.5)^{* *}$ \\
$N$ & 5,529 & 6,433 \\
\hline
\end{tabular}

Note that the number of observations is smaller than in the estimates of Table 2 because for males (females) 54 (45) the duration at the job (either completed or incomplete) is missing are therefore these individuals are removed from the sample. Not reported are the other parameter estimates; absolute t-statistics in parentheses; a ** (*) indicates significance at a $95 \%(90 \%)$ level

\subsubsection{The Duration of Temporary Jobs Reconsidered}

Our theory predicts that there is a positive correlation between the expected duration of a job and the size of the benefit expiration spike. We showed that indeed for permanent jobs there is a larger spike in the job finding rate than for temporary jobs. However, there is a large variation in the duration of temporary jobs. Some ex ante temporary jobs turn out to be ex post long employment spells. Our theory also predicts that the benefit expiration spike should be bigger for long temporary jobs.

To investigate a first impression whether indeed shorter temporary jobs are less likely to generate benefit expiration spikes in the transition rate to these jobs, as before we calculated the relative spike as the job finding rate in the month of benefit expiration divided by the job finding rate in the month previous to that. ${ }^{18}$ The results of these calculations are shown in columns (3) and (4) of Table 1. For males with a potential benefit duration of 6 months the relative spike for short-term temporary jobs is 0.79 , i.e. there is no spike at all. For the same category of workers the relative spike for long-term temporary jobs equals 1.76 . On average there is no relative spike for short-term jobs while the relative spike for long-term jobs is 1.82 . These findings confirm our theoretical model. For females the results are less clear. On average there are spikes for short-term temporary jobs and for long-term temporary jobs. The last type of spike is larger than the first type but the differences are small. This is consistent with our results (in Propositions 1 and 2) that for workers with higher value of home production (assuming this is the case for women) both types of jobs are postponed and the difference in delay is smaller (compared to workers with lower $\sigma$ ).

\subsection{The Slovenian Labor Market Reconsidered}

An important issue that may arise when analyzing the Slovenian labor market is the interpretation of behavior of workers in relation to the informal sector. Vodopivec

\footnotetext{
18 Note that some job durations were right censored with a duration less than 1 year. This causes a bias in the calculations for jobs that lasted less than 1 year.
} 
Table 5 Parameter estimates spikes-before and after the 1998 reform

\begin{tabular}{llll}
\hline & Permanent jobs & Temporary jobs & Observations \\
\hline Males & & & \\
Before & $1.51(8.4)^{* *}$ & $0.58(4.5)^{* *}$ & 2,741 \\
After & $1.89(6.6)^{* *}$ & $0.51(2.9)^{* *}$ & 2,842 \\
Total & $1.63(11.3)^{* *}$ & $0.59(6.1)^{* *}$ & 5,583 \\
Females & & & \\
Before & $1.56(9.4)^{* * *}$ & $0.72(6.4)^{* *}$ & 3,119 \\
After & $1.61(5.2)^{* *}$ & $0.61(4.0)^{* *}$ & 3,359 \\
Total & $1.60(11.6)^{* *}$ & $0.66(7.8)^{* *}$ & 6,478 \\
\hline
\end{tabular}

The "total" estimates are the same as those reported in Table 2 panel c; absolute t-statistics in parentheses; a ** (*) indicates significance at a $95 \%(90 \%)$ level

(1995) indicates that in the early 1990s unemployed workers is Slovenia might have collected unemployment compensation and work at the same time under informal employment. Vodopivec claims that during 1990-1992 there was a tendency among the recipients of unemployment benefits in Slovenia to stay unemployed until their benefits expired before taking a job. If so, benefit exhaustion spikes would not have much to do with delay behavior as we claim. Instead, they would simply reflect the end of a waiting for benefits to expire period. Nevertheless, Slovenian legislators in 1993 and 1994 enacted several laws to prevent this type of waiting behavior from happening. In 1998, there was a major reform of unemployment benefits drastically reducing the potential benefit duration, roughly by half for most groups of recipients. As indicated by Van Ours and Vodopivec (2006), the 1998 reform also called for several measures aimed at speeding up benefit recipients' reemployment, including improvement in employment services, the obligatory preparation of a reemployment plan for each benefit recipient, and more frequent contact between counselors and recipients. Furthermore, reform called for stricter monitoring of eligibility. Benefit recipients had to make themselves available to employment office counselors several hours a day. For the first time, inspectors (a special arm of employment offices) would check to see if benefit recipients were in fact unemployed (inter alia, by paying home visits to benefit recipients) and actively searching for a job. To the extent that collecting benefits and working in the informal sector until benefits expire was an issue, this should have been more prevalent before the 1998 reform. Tougher monitoring of the unemployment status accompanied by occasional benefit sanctions should have ruled out a lot of this type of abuse. Nevertheless, to investigate this issue in more detail we performed separate estimates on data collected before and after the reform. Table 5 shows the relevant parameter estimates. Clearly there is no tendency for exhaustion spikes in the job finding rates to be smaller after the reform. And, the difference in the size of the spikes between permanent jobs and temporary jobs is present as much after the reform as it was before the reform. From this we conclude that although we cannot rule out some influence of the informal sector, this doesn't seem to be an important explanation for the existence of the end-of-benefit spikes. 


\section{Conclusions}

Putting a limit on the duration of unemployment benefits tends to introduce a "spike" in the job finding rate just before benefit exhaustion. This phenomenon may not be important from a quantitative point of view since it occurs when many unemployed have already left unemployment, but it does raise the question why it occurs.

Our study presents a theoretical model in which the nature of the job affects the size of the end-of-benefit spike. In our model, spikes in the job finding rates are caused by delays between job finding and the start of the job. Workers prefer to delay and make an offer to the firm about the starting date for the job. The firm will only accept a delay if the value of the job including delay is larger than the value of searching for a new worker, who may (also) have a preference for delay. When workers decide about their offer to the firm they take into account that the firm might reject the offer if the delay is too long. They also take into account that long-lasting jobs have more value to the firm so for these jobs employers are more likely to accept longer delays. From our theoretical model we derive that delays are more likely to occur for permanent jobs than for temporary jobs. Our model assumes that workers who have found a job will never delay the start of the job beyond the expiration date of their benefits, since that would be too costly. This causes many unemployed to leave unemployment at benefit exhaustion thus causing a spike in the job finding rate. Since the delay period is longer the size of the end-of-benefit spike will be larger for permanent jobs than for temporary jobs. We investigate the validity of our model using Slovenian unemployment data which have the unique feature that the temporary or permanent nature of the post-unemployment job is registered. Indeed, we find that spikes are more likely to occur in transitions from unemployment to permanent jobs. From this, we conclude that end-of-benefit spikes in job finding rates are related to optimizing behavior of unemployed workers who rationally assume that employers will accept delays in starting date of a new job. Thus the spikes in the job finding rate suggests that workers exploit unemployment insurance benefits for subsidized leisure.

Our paper also makes a theoretical contribution. Previous studies refer to two alternative explanation for the existence of such a spike. First, a static labor supply model in which a kink in the budget constraint causes many individuals to choose the same benefit duration. Second, a non-stationary search model in which the job finding rate is slowly increasing due to increasing search intensity and falling reservation wages. In neither of the two models the nature of the job is important. Our theoretical model is not intended to replace existing theories of job search. We introduce a new element in job acceptance behavior that enriches traditional job search theory by showing that the nature of the job may influence behavior as workers get closer to benefit exhaustion.

\section{Appendix: Variables Used in the Analysis}

In the analysis we use the following variables:

- Age: continuous variable

- Education: dummy variables, Education2 = elementary school, Education3 = vocational school, Education4 = high school or more, reference group $=$ unfinished elementary school 
Table 6 Means of variables

\begin{tabular}{llllll}
\hline & Males & Females & & Males & Females \\
\hline Age/10 & 3.24 & 3.16 & Group 2 & 0.19 & 0.18 \\
Educ2 & 0.27 & 0.23 & Group 3 & 0.16 & 0.18 \\
Educ3 & 0.42 & 0.32 & Group 4 & 0.23 & 0.20 \\
Educ4 & 0.26 & 0.41 & Group 5 & 0.18 & 0.18 \\
Reference & 0.05 & 0.04 & Group 6 & 0.17 & 0.17 \\
& & & Reference & 0.07 & 0.09 \\
Family1 & 0.20 & 0.26 & & & \\
Family2 & 0.28 & 0.42 & Permanent job & & \\
Reference & 0.52 & 0.32 & Completed duration & 0.35 & 0.36 \\
& & & Incomplete duration & 0.65 & 0.64 \\
Bad health & 0.08 & 0.06 & & & \\
Reference & 0.92 & 0.94 & Temporary job & & \\
& & & Completed duration & 0.66 & 0.60 \\
Temporary job & 0.54 & 0.51 & Incomplete duration & 0.34 & 0.40 \\
Permanent job & 0.18 & 0.14 & & & \\
Incomplete spell & 0.28 & 0.34 & Observations & 5,583 & 6,478 \\
\hline
\end{tabular}

- Family situation: dummy variables, Family $1=1$ dependent family member, Family $2=$ more than 1 dependent family member, reference group $=$ no dependent family members

- Ill health: Dummy variable derived from information obtained by employment office councilors from interviews with benefit recipients

- Potential Benefit Duration (PBD) and time of entrance into unemployment (before or after the policy change): 5 dummy variables, Group $2=$ PBD of 9 months, entrance before, Group $3=$ PBD of 6 months, entrance after, Group $4=$ PBD of 12 months, entrance before, Group $5=$ PBD of 6 months, entrance after, Group $6=$ PBD of 9 months, entrance after; reference group $=$ PBD of 6 months, entrance before.

The characteristics of our dataset are presented in Table 6.

Open Access This article is distributed under the terms of the Creative Commons Attribution License which permits any use, distribution, and reproduction in any medium, provided the original author(s) and the source are credited.

\section{References}

Adamchik, V. (1999). The effect of unemployment benefits on the probability of re-employment in Poland. Oxford Bulletin of Economics and Statistics, 61, 95-108.

Atkinson, A., \& Micklewright, J. (1991). Unemployment compensation and labor market transitions: A critical review. Journal of Economic Literature, 29, 1697-1727.

Card, D. E., \& Levine, P. B. (2000). Extended benefits and the duration of UI spells: Evidence from the New Jersey extended benefit program. Journal of Public Economics, 78, 107-138. 
Card, D. E., Chetty, R., \& Weber, A. (2007). The spike at benefit exhaustion: Leaving the unemployment system or starting a new job? American Economic Review, 97, 113-118.

Carling, K., Harkman, P. A., \& Holmlund, B. (1996). Unemployment duration, unemployment benefits, and labor market programs in Sweden. Journal of Public Economics, 59, 313-334.

Katz, L. F., \& Meyer, B. D. (1990a). The impact of the potential duration of unemployment benefits on the duration of unemployment. Journal of Public Economics, 41, 45-72.

Katz, L. F., \& Meyer, B. D. (1990b). Unemployment insurance, recall expectations, and unemployment outcomes. Quarterly Journal of Economics, 105, 973-1002.

Lalive, R., Ours, J. C., \& van Zweimüller, J. (2006). How changes in financial incentives affect the duration of unemployment. Review of Economic Studies, 73, 1009-1038.

Meyer, B. D. (1990). Unemployment insurance and unemployment spells. Econometrica, 58, 757-782.

Moffitt, R. (1985). Unemployment insurance and the distribution of unemployment spells. Journal of Econometrics, 28, 85-101.

Moffitt, R., \& Nicholson, W. (1982). The effect of unemployment insurance on unemployment: The case of federal supplemental benefits. The Review of Economics and Statistics, 64, 1-11.

Mortensen, D. T. (1977). Unemployment insurance and job search decisions. Industrial and Labor Relations Review, 30, 505-517.

Roed, K., \& Zhang, T. (2003). Does unemployment compensation affect unemployment duration? Economic Journal, 113, 190-206.

Van den Berg, G. J. (1990). Nonstationarity in job search theory. Review of Economic Studies, 57, $255-277$.

Van Ours, J. C., \& Vodopivec, M. (2006). How shortening the potential duration of unemployment benefits affects the duration of unemployment: Evidence from a natural experiment. Journal of Labor Economics, 24, 351-378.

Van Ours, J. C., \& Vodopivec, M. (2008). Does reducing unemployment insurance generosity reduce job match quality? Journal of Public Economics, 92, 684-695.

Vodopivec, M. (1995). Unemployment insurance and duration of unemployment: Evidence from Slovenia's transition. Policy Research Working Paper, 1552, World Bank. 